\title{
E-portfolio implementation: Examining learners' perception of usefulness, self-directed learning process and value of learning
}

\author{
Boon Khing Song \\ Republic Polytechnic, Singapore
}

\begin{abstract}
Electronic portfolios (e-portfolios) have been widely used to help learners collect evidence of their learning, reflect on their evaluation, and promote self-directed learning. Through the introduction of an e-portfolio platform in a cluster of lessons in a module in a polytechnic in Singapore, this paper aimed to evaluate the effectiveness of the e-portfolio through the learners' perceptions. A cross-sectional design using an online survey was employed with 226 students taking part in this study. There was high internal consistency among the survey items. Exploratory factor analysis suggested a 5-factor structure: (1) perceived usefulness (PU), (2) organisation (ORG), (3) collaboration (COL), (4) evaluation (EVA), and (5) perceived value of learning (PVL). In addition, confirmatory factor analysis verified that the proposed 5-factor solution was a good model fit. The final research instrument comprised 19 items. A further multiple regression analysis showed that all the independent variables, except for evaluation, were positive and significant predictors of learners' PVL. Specifically, the ORG variable was the most influential predictor of PVL. In comparison, the PU variable was a relatively weaker predictor of PVL. The practical implications and further direction for research are discussed in the paper.
\end{abstract}

\section{Implications for practice:}

- Curriculum designers could leverage on the use of Padlet as an e-portfolio as it has shown to be a promising tool in scaffolding students to practice self-directed learning.

- Curriculum teams could increase learners' perceived usefulness of e-portfolios by allowing learners to be familiarised with the tool in earlier phases of the curriculum.

- Curriculum leaders may need to orchestrate carefully the technological, learning processes, and the affective aspects of learners to promote self-directed learning.

Keywords: e-portfolios, quantitative, survey, exploratory factor analysis, confirmatory factor analysis, multiple linear regression

\section{Introduction}

In the socio-constructivist learning environment, learners learn through a series of processes, from prior knowledge activation, active seeking of information, collaborative learning to deep learning, and reflection. It is an ongoing process that requires learners to put on their metacognitive caps to delve deeper into the process and product of their learning. It was postulated by Strampel and Oliver (2007) that technology can be harnessed to help learners to be better reflective practitioners and to promote critical evaluation. In addition, the effective use of technology can help learners to self-track and monitor their own learning progresses more easily and efficiently. In particular, an electronic portfolio (e-portfolio) allows learners to register their learning and reflection anytime anywhere and is a pedagogical tool to collect evidence of learning as well as engage in peer collaboration and assessment. The conceptual underpinning of an eportfolio is in unison with the constructivist approach and is defined by Barret (2010) to be a purposeful assemblage of learners' work that focuses on their efforts, progress, and achievements.

There are many e-portfolio platforms being used by schools, colleges, and universities. Among the more commonly used are FolioSpaces, Blackboard ePortfolio, Digication ePortfolios, Mahara, and Elgg. These are systems that are either incorporated using free hosting services, residing within an institutional learning management system or operating on open source. Padlet is an online application that allows users to create a bulletin board for organising and displaying of information. Images, links, pictures, and videos can be added onto the Padlet learning canvas as digital evidence of students' learning which can then be shared with classmates or teachers. As such, Padlet is a powerful learning tool for tracking of students' learning progresses, promoting self-reflection and self-directed learning. Despite these useful affordances, Padlet is not used traditionally as an e-portfolio pedagogical tool. 
On the psychological learning front, self-directed learning involves the learners taking responsibility for their own learning by strategising the ways information is curated and reviewed as well as taking an active role in the process of reflection before final evaluation is carried out (Gencel \& Saracaloglu, 2018). Specifically, Knowles (1975, p.15) defines self-directed learning as:

A process in which individuals take the initiative, with or without the help of others, in diagnosing their learning needs, formulating learning goals, identifying human and material resources for learning, choosing and implementing appropriate learning strategies, and evaluating learning outcomes.

The use of an e-portfolio can, in fact, facilitate the acquisition of self-directed learning skills. For instance, Britland (2019) found that students who were involved in an e-portfolio peer mentoring group that focussed on an extracurricular programme developed the capacity for greater self-directed learning. The students were more willing to take charge of their own learning and provide peer support with the assistance of the e-portfolio tool.

While the benefits of the use of e-portfolios in facilitating students' self-directed learning have been heavily endorsed in the literature, there are often implementation issues associated with using e-portfolios as a formative pedagogical learning tool in a curriculum. Careful consideration has to be undertaken in order for this learning tool to be successful adopted by students in their learning. This includes understanding students' perspectives in the usefulness of this learning tool as well as the overall perceived effectiveness of e-portfolios in developing self-directed skills and improved learning experience (McNeill \& Cram, 2011). To date, there is a paucity in extant research literature on learners' perceived value of learning towards the use of e-portfolios in facilitating self-directed learning processes.

Therefore, this study seeks to examine the perception of learners after using a newly introduced technological tool, Padlet, as an e-portfolio system to support their self-directed learning in a critical thinking and problem solving module offered by a polytechnic in Singapore. To better understand the conditions that facilitate an effective usage of the Padlet as an e-portfolio to support self-directed learning, there is a need to identify the various perceived learning constructs in this study. Hence, the following research questions were crafted to address the aim of this study:

1. What are the perceptions of the learners towards e-portfolio usage?

2. What is the relationship between the processes of self-directed learning, perceived usefulness of the e-portfolio platform, and perceived value of learning?

3. To what extent do the processes of self-directed learning and perceived usefulness of the eportfolio platform predict the perceived value of learning towards e-portfolio usage?

\section{Literature Review}

\section{Different types of e-portfolios}

As advocated by Jaryani et al. (2010), there are predominantly three types of e-portfolio: (1) developmental, (2) reflective, and (3) representational. Firstly, a developmental e-portfolio is a work in progress display of the work that the owner of the e-portfolio has accumulated over a period of time. Attempts will also be made to link the learner's work to learning outcomes and criteria of assessment rubrics. On the other hand, a reflective e-portfolio involves the learners making sense of what they have learnt and relating to authentic experiences. At this stage, the learners will carry out self-reflection, to understand more about their strengths and weaknesses, that is realisation of self-competency, after which, the learner will be provided with opportunities to improve their work based on the feedback obtained from teachers and peers, as well as self-evaluation that was carried out after self-reflection. Lastly, a representational e-portfolio showcases the achievement of the owner with regards to their desired goals or the learning outcomes. As such, the work demonstrated in this portfolio is selective and represents the peak achievement of the owners as they progress and develop over a period of time (Jaryani et al., 2010). In fact, Garthwait and Verrill (2003) argued that the underpinning concept of e-portfolios is centred on the learning process, rather than the product of learners. Similarly, Barret (2010) highlighted the importance of the reflection and critical thinking displayed during the construction phase of e-portfolio usage. In this study, the reflective e-portfolio was the most appropriate type to be adopted in the described curriculum routine. 


\section{Proposed conceptual framework of the e-portfolio}

The formative evaluation developmental model developed by Wolf (1994) is proposed to be the conceptual framework to be adopted for the e-portfolio in this study. It is an appropriate model because the concepts advocated are in alignment with the investigation of self-directed learning experienced by the students in the described module. The conceptual model is shown in Figure 1. In the formative evaluation model, the construction phase, as propounded by Wolf (1994), is described as follows:

(i) Collection, organising, and presenting: Students will start to plan for their e-portfolio and adopt a structured and organised manner of working in a personalised manner. During the process, there will be attempt for students to connect new ideas with existing ones and integrate their evidence of learning with authentic experience.

(ii) Scaffold, consultation, and collaboration: In this step, students will further develop their social and cognitive skills through collaboration and interaction of ideas between team members or teacher. Students will also be mindful of the need to activate their prior knowledge and experience and build on them to create new knowledge. Social experience is touted to be an essential step to trigger off new insights and ideas.

(iii) Feedback collected through the process of self-reflection, self-evaluation, peer, and teacher evaluation: At this stage, students are given the chance to make sense of their concrete experiences and realise their self-worth and competence. This often occurs through comparison of reflections done between learners, exchange of feedback between different peers during peer-evaluation and pegging their current standards to the expected performance indicators or learning outcomes.

\section{Collection, organising and} presenting

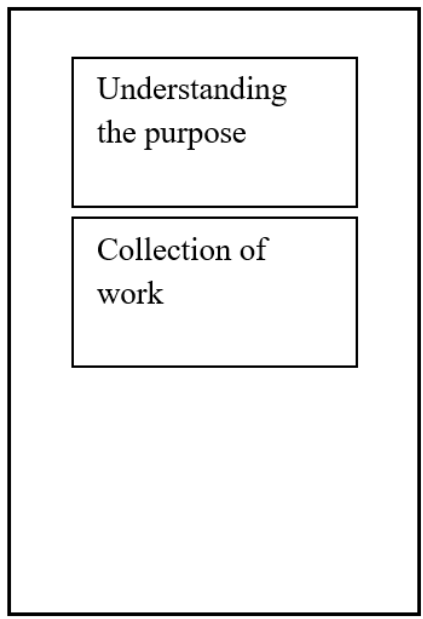

Scaffold, consultation and collaboration

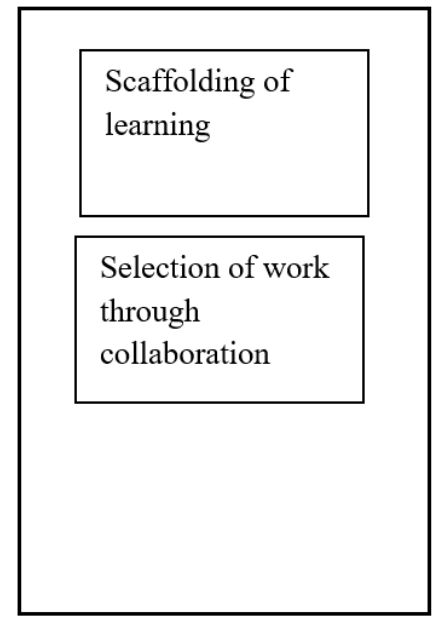

Self-reflection, self-evaluation, peer and teacher evaluation

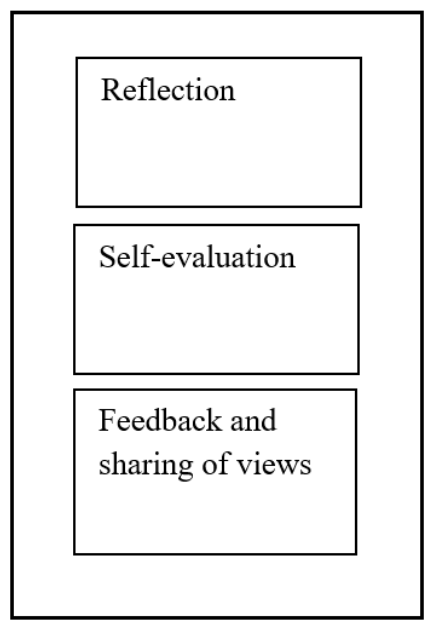

Figure 1. Conceptual model of the formative evaluation model

\section{E-portfolios facilitation of self-directed learning}

E-portfolio is a learner-centred tool that can aid learners in triggering independent learning and enhancing the development of their self-directed skills. Most studies that examined self-directed learning skills developed in e-portfolio usage focussed on the readiness of learners to engage in self-directed learning after experiencing learning with e-portfolios (Abu Awwad, 2013; Goliath, 2009; Huang, 2006)). For instance, in the study done by Gencel and Saracaloglu (2018), a self-directed learning readiness scale was administered to pre-service teachers to find out about their self-direction, learning will, and self-control. In another study by Beckers (2019), the development of self-directed learning skills in students were assessed by their accuracy in self-assessment and the quality of work produced. Hence, self-directed learning was judged based on learners' product of learning rather than the process of learning. 
However, the process of learning is central to the dynamic teaching and learning system (Biggs, 2001). Measurement of perceived learning process will also allow insights about the quality of the educational experience of learners and provide opportunities for program designers to adjust and review subsequent implementations (Vaisman, 2012). As posited by Biggs (2001) in his 3P model (presage, process, and product), the approaches to learning in the learners' perspectives can be broken down into three stages: (1) planning of learning behaviour (through prior knowledge, competence and learning preferences), (2) learning process execution (for instance, engaging in reflection and linking concepts learnt). and (3) product of learning (what the learners have achieved and their sense of learning satisfaction). In the investigation of 1490 students from University of Almeria and Granada (Spain) in an education programme, the teaching and learning process of students was examined to identify the potential factors that affected students' satisfaction (De La Fuente et al., 2011). Besides gaining insights from the different personal and contextual factors that influenced students' perspectives of the teaching and learning process outcome, the study also revealed the systemic calibration between the teaching and learning processes. As evidenced, the significance of the learning processes of learners cannot be overly emphasised. It is also noteworthy that the product phase in Biggs's 3P model describes learners' experience in the different teaching contexts in different classes and disciplines. Henceforth, in this study, the focus will be on learners' perception of the processes of self-directed learning while using e-portfolios to support their learning.

\section{Perceived usefulness of e-portfolios}

The technology acceptance model (TAM) developed by Davis (1985) is a robust and common framework used in investigating users' technology adoption behaviour (Rahmi et al., 2018). To ensure the effectiveness of the e-portfolio implementation in this study, it was pertinent to understand the factors that influence learners' acceptance and rejection of e-portfolios. In the TAM model, there are several connecting variables such as perceived ease of use (PEU), perceived usefulness (PU), attitude to use (AT), and behavioural intention (BI). According to Davis (1989), PEU and PU are the most important sub-constructs in this model as they mainly influence an user's acceptance or rejection of the technology introduced (Abdullah et al, 2016; Chen et al., 2012). PEU is defined as "the degree to which a person believes that using a particular system would be free of effort" (Davis, 1989, p. 320). On the other hand, PU refers to "the degree to which a person believes that using a particular system would enhance his or her job performance" (Davis, 1989, p. 320). PEU and PU are also extrinsic motivational belief factors in influencing users to continue using the adopted technology or system. In this study, learners' PU was examined and not the PEU, AT, and BI variables for several reasons. Firstly, PEU influences PU and has either a direct or indirect relationship to BI to use a particular system through PU (Bhatiasevi, 2011; Butler Lamar, 2016; Davis, 1989). In this study, the main emphasis was on finding out the perception of value of learning and processes of self-directed learning. Hence the PU was investigated and not PEU. Secondly, recent studies have revealed that the AT factor has a weak correlation with the BI and PU variables in the model and hence was excluded from investigation (Bhatiasevi, 2011; Teo, 2009; Ursavaş, 2013). Thirdly, from a meta-analysis conducted that examined user acceptance in e-learning systems, it was found that the relationship between the TAM variables and user satisfaction, rather than attitude, yielded the best results (Rahmi et al., 2018). These findings corroborated with the author's decision to drop the AT variable and to seek another more appropriate affective variable to focus more on the value of learning that learners have derived from the use of e-portfolios in this study.

\section{Perceived value of learning}

In an internalisation study conducted by Deci (1994), the value/usefulness subscale was used to determine the participants' perception of the value of the task performed after the participants have been subjected to a self-regulated activity. This was essential in finding out whether the subjects have internalised, either in the form of introjection or integration, the regulation of an uninteresting but yet important activity. Hence, the use of the sub-construct perceived value in relation to the internalisation of a self-regulated activity was of high interest to the author and important in this study. There was also a further example of the use of the value/usefulness subscale from the Intrinsic Motivation Inventory developed by Deci (1991). In another study exploring preschool and primary school teacher students' perception on the value/usefulness of eportfolios, Ciesielkiewicz (2019) reported that students' perception of the value of e-portfolios was the greatest influencing factor on intrinsic motivation, indicating a high tendency for students to be engaged and intrinsically motivated. Based the abovementioned findings, it appeared that learners' perceptions of 
the value of their learning have to be taken into consideration to support the successful implementation of a technology tool or programme for learning. Consequently, the measurement of perceived value of learning (PVL) was appropriate in this study as it is a construct, together with perceived usefulness, relevant to the concept of learners' motivation (Deci, 1991). Also, the PVL is a potential affective variable to replace the AT variable (as mentioned earlier) in this study due to its close proximity to learning processes. From the learner's perspective, challenges with the usefulness of e-portfolios as well as the satisfaction of the process of learning will in turn affect their motivation, either in a positive or negative manner (Kwok, 2011; Tuksinvarajarn, 2009). Taken together, the three main constructs: perceived usefulness, perceived processes of self-directed learning, and perceived value of learning were investigated to offer more insights into the multi-faceted perception of learners towards the use of e-portfolios.

\section{Method}

\section{Background}

In this study, the polytechnic of the investigated critical thinking and problem solving module specialises in the instructional approach of problem based learning. In tandem with the socio-constructivist approach, students in the polytechnic are given opportunities to activate their prior knowledge, construct new knowledge based on active engagement in information finding, scaffolding from facilitators, peer collaboration, and reflection. Specifically, for the described mandatory module for mainly Year 1 students in the institution, learners are exposed to critical thinking skill concepts such as claims and arguments, types of argument, various cognitive biases, and logical fallacies, and good critical thinking dispositions, for instance, open-mindedness, scepticism and empathy. In Lessons 1 to 9, learners made use of the institution's learning management system for assessment and reflection purposes for each lesson. However, Lessons 10 to 12 were presented in the form of a large problem context that mirrors a real world complexity - countering terrorism. For the first time, learners were introduced to Padlet as an e-portfolio to help them in the collection, selection, organisation, collaboration, evaluation, and reflection processes. For instance, when learners received the staggered information throughout the sessions, they would at the onset, evaluate the credibility of the sources in their teams. Next, through active co-reasoning between team members, the selected information was organised and connected on the Padlet platform. In addition, feedback dialogic exchanges between the lecturers and learners took place to support the teams in enhancing the quality of evaluation performed on the e-portfolio. Finally, learners were encouraged to reflect on their learning processes and experiences on Padlet to deepen their understanding of concepts.

\section{Research design and participants}

This quantitative study employed a non-experimental cross-sectional design using an online survey administrated at the end of Lesson 12. A total of 226 students who took part in this study. Ethics approval from the researched polytechnic's institutional review board was obtained prior to the start of this current study. Students were informed by the lecturers as well as through the online consent form that their responses would be treated with confidentiality and they could withdraw from the study at any time during or after the research period. Most importantly, it was communicated to the students that their responses would not contribute to any of the assessment components stipulated for the module. Student generally took appropriately 15 minutes to complete the survey.

\section{Instrument}

The survey comprised two main sections, one section examined the demographic profile of the respondents while the other section addressed the aforementioned constructs of the research model. To measure learners' PU towards the use of the e-portfolio, the relevant items from TAM were adapted and modified to suit the local context (Davis, 1989). The items for the process of self-directed learning construct were crafted mainly with reference to the self-directed learning process described in the formative evaluation model (Wolf, 1994). In addition, the items in the PVL were adapted from the selected value/usefulness subscale of the Intrinsic Motivation Inventory from Deci (1991) to assess the perceived value of learning of learners throughout these three lessons, that is Lessons 10 to 12. All scale items were rated based on a 5-point Likert scale represented as follows: 1 - strongly disagree; 2 - disagree, 3 - neither agree nor disagree; 4 -agree, and 5 - strongly agree. It should be noted that all the items relating to the cognitive skills required of self- 
directed learners were asked in relation to the use of the Padlet tool. In total, there were 21 items in this scale and they are discussed in further detail in the next section.

\section{Instrument validation}

Prior to the measurement of students' perception of effectiveness of using Padlet to facilitate self-directed learning, the survey instrument used needed to possess a sufficiently strong psychometric quality. As such, the author employed the scale validation protocol proposed by Spector (1992) to ensure that the results collected from this research demonstrate adequate reliability and validity in relation to the researched construct in order to make appropriate and robust conclusions. First and foremost, the scale items were checked by two researchers (who also facilitated the described module) for face and content validity. Next, the internal consistency of the items in the scale were examined using Cronbach's alpha obtained via the SPSS statistical software version 24.0. Likewise, the SPSS software was utilised to conduct exploratory factor analysis (EFA) for establishing construct validity for the self-directed learning processes. As mentioned earlier, the items crafted to measure self-directed learning processes were based on the conceptual understanding of the formative evaluation model. Hence, there was a necessity to explore the underlying conceptual structure of the items by using EFA. Thereafter, the derived factor structure generated from EFA was further subjected to stability and reliability assessment via the use of confirmatory factor analysis (CFA). The open source package Lavaan for R (Rosseel, 2011) in the Rstudio version 1.2.1335 software was used for this purpose.

\section{Reliability}

Using the SPSS software, the Cronbach's alpha reading for the scale instrument was found to be .92, exceeding the common threshold of .70 (Hair et al., 1998) which indicated high internal consistency for the items. The item-total correlation has values ranging from .51 to .69 , above the minimum cut-off value of .3 as proposed by Cristobal et al. (2007).

\section{Validity}

To further explore and verify the factor structure of the self-directed learning processes, EFA was conducted. In addition, the rigour of the construct validity of the entire scale was tested using CFA.

\section{Exploratory factor analysis (EFA)}

For EFA, the principal axis factoring analysis with promax rotation was performed to explore the factor structure of the investigated construct. Prior to the conduct of EFA, the Kaiser-Meyer-Olkin (KMO) test measurement of sampling adequacy - was carried out and revealed a value of .91, indicating that the sample size was adequate to perform factor analysis. In addition, Bartlett's Test of Sphericity was statistically significant $(p<.001)$, further justified the data was likely to be factorisable. The results yielded a 5-factor solution that accounted for $72 \%$ of the total variance as indicated in Table 1. Also, the EFA factor loadings were all within the range of .44 to .99 . However, two items failed to load on any of the factors. As depicted in Table 1, there were five items loaded on Factor 1 and 2, four items loaded on Factor 3, three items loaded on Factor 4, and two items loaded on Factor 5. Internal reliability amongst the items in each factor was high as demonstrated by the Cronbach alpha values of $.98, .85, .87, .90$ and .89 in Factors 1 to 5 respectively. The final instrument has 19 items. 
Table 1

Pattern matrix of the items loaded onto the five factors

\begin{tabular}{|c|c|c|c|c|c|c|}
\hline No. & Item & 1 & 2 & 3 & 4 & 5 \\
\hline 1 & $\begin{array}{l}\text { Using Padlet enables me to complete my work more } \\
\text { quickly. }\end{array}$ & .91 & & & & \\
\hline 2 & Using Padlet increases my productivity. & .97 & & & & \\
\hline 3 & Using Padlet enhances my effectiveness in learning. & .94 & & & & \\
\hline 4 & Using Padlet makes it easier in my learning. & .94 & & & & \\
\hline 5 & I find Padlet useful in my learning. & .95 & & & & \\
\hline 6 & $\begin{array}{l}\text { I reflected on the feedback given by fellow team } \\
\text { mates. }\end{array}$ & & .59 & & & \\
\hline 7 & I reflected on the learning process in the lessons. & & .79 & & & \\
\hline 8 & I made written records on my learning progress. & & .84 & & & \\
\hline 9 & I share my findings and views with team mates. & & .66 & & & \\
\hline 10 & I share my findings and views with my facilitator. & & .74 & & & \\
\hline 11 & $\begin{array}{l}\text { I am aware of the deadlines for completing the tasks } \\
\text { of the lessons. }\end{array}$ & & & .66 & & \\
\hline 12 & I am aware of the resources given to me. & & & .97 & & \\
\hline 13 & $\begin{array}{l}\text { I am aware of the resources needed for the } \\
\text { completion of the tasks. }\end{array}$ & & & .85 & & \\
\hline 14 & $\begin{array}{l}\text { I summarised the collected information in order to } \\
\text { help me complete the tasks. }\end{array}$ & & & .44 & & \\
\hline 15 & $\begin{array}{l}\text { The learning activities in off-campus learning (OCL) } \\
\text { Lesson } 10 \text { were useful for building up my } \\
\text { understanding of this unit. }\end{array}$ & & & & .80 & \\
\hline 16 & $\begin{array}{l}\text { The learning activities in Lesson } 11 \text { were useful for } \\
\text { building up my understanding of this unit. }\end{array}$ & & & & .99 & \\
\hline 17 & $\begin{array}{l}\text { The learning activities in Lesson } 12 \text { were useful for } \\
\text { building up my understanding of this unit. }\end{array}$ & & & & .80 & \\
\hline 18 & $\begin{array}{l}\text { The team made a collective decision on selecting the } \\
\text { key information. }\end{array}$ & & & & & .79 \\
\hline 19 & $\begin{array}{l}\text { The team collectively helped to connect the key } \\
\text { pieces of information. }\end{array}$ & & & & & .87 \\
\hline \multicolumn{2}{|r|}{ Eigenvalue } & 9.38 & 3.75 & 1.43 & .96 & .93 \\
\hline \multicolumn{2}{|c|}{ Explained total variance $(\%)$} & 43.29 & 60.39 & 65.88 & 69.06 & 72.03 \\
\hline
\end{tabular}

Note. 1 - Factor 1; 2 - Factor 2; 3 - Factor 3; 4 - Factor 4 and 5 - Factor 5

Confirmatory factor analysis (CFA)

Using the open source package Lavaan for R (Rosseel, 2011), CFA was further employed to test if the proposed 5-factor model generated from EFA was stable and of good internal consistency. Before proceeding to analyse the suggested factor structure, it was crucial to examine the multivariate normality of the data points. West et al. (1995) proposed using a reference of absolute skewness value of $<2$ and absolute kurtosis value $<7$ to establish the normality of the observed variables. Using SPSS statistical software version 24.0, all the scale items were observed to have skewness and kurtosis values ranging from $|.06|$ to $|2.2|$, thereby fulfilling the recommendation of normality by West et al. (1995). In addition, the sample size of 226 respondents exceeded the proposed minimum size of 200 by Kline (2015). Hence, taking these observations together, the data were suited for CFA. Next, the fit measures for the measurement model were calculated to determine how well the model fitted the data obtained. The latent factors were standardised, enabling that all factor loadings to be freely estimated. It was found that the model fit was deemed acceptable with all fit measures meeting the requirements for satisfactory fit $\left(\chi^{2} / \mathrm{df}<3.00\right.$; RMSEA $<0.08$; SRMR < 0.08; CFI > 0.90; and TLI > 0.90) proposed by Byrne $(2010): \chi^{2} / \mathrm{df}=2.60, p<.001$; $\mathrm{RMSEA}=0.084$; $\mathrm{SRMR}=0.052 ; \mathrm{CFI}=0.94$; and TLI $=0.93$. In addition, all items loaded significantly on the latent factors with values ranging from 0.46 to 1.10 . The proposed model used in this study is shown 
in Figure 2 below with the following labelling: Factor 1 (perceived usefulness, PU); Factor 2 (evaluation, EVA); Factor 3 (organisation, ORG); Factor 4 (perceived value of learning, PVL) and Factor 5 (collaboration, COL). To further classify the factors, the PU was used to investigate the perception of learners towards the e-portfolio technological platform while the ORG, COL, and EVA factors addressed the self-directed learning processes aspect. Lastly, PVL attempted to measure the affective component of learners towards their learning. Finally, based on these findings, it was concluded that the survey instrument possessed strong psychometric reliability and validity to assess students' perception in the use of eportfolios to engage them in self-directed learning.

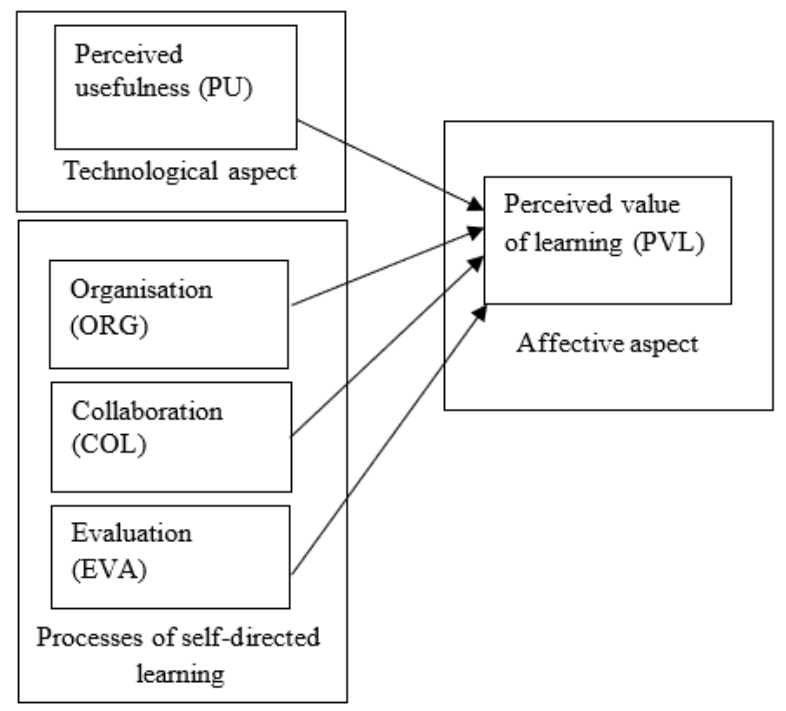

Figure 2. Proposed 5-factor model of perceived value of learning via self-directed learning processes and perceived usefulness of the use of e-portfolios

\section{Result analysis}

\section{Descriptive statistics}

The descriptive statistics for all the survey items were obtained as reflected in Table 2. Additionally, the breakdown for the items in the different factors are detailed as such: items 1 to 5 are in the PU factor; items 6 to 9 are in the ORG factor; items 10 to 11 are in the COL factor; items 12 to 16 are in the EVA factor, while items 17 to 19 are in the PVL factor. All items in the scale garnered above average mean rating (above 3 ) in a 5-point scale survey. In particular, the means for item 6 (I am aware of the deadlines for completing the tasks of the lessons.), item 11 (The team collectively helped to connect the key pieces of information.) and item 15 (I share my findings and views with team mates.) were high, with $M=4.35,4.24$, and 4.27 respectively. On the contrary, the mean rating for items in the PU factor were relatively lower, with all values below 4. Specifically, the three items with the lowest mean ratings were item 1 (Using Padlet enables me to complete my work more quickly.), item 2 (Using Padlet increases my productivity.) and item 3 (Using Padlet enhances my effectiveness in learning.) with $M=3.38,3.36$, and 3.40 respectively. On the whole, the standard deviations of the items in the PVL, ORG, COL, and EVA factors were generally lower than the standard deviations of the items in PU factor, suggesting that the perception of learners in the usefulness of portfolios were more diverse than their self-directed learning processes and perceived value of learning. 
Table 2

Descriptive statistics of survey items

\begin{tabular}{cccc}
\hline Item & Mean & Standard deviation & Factor \\
\hline 1 & 3.38 & 1.177 Perceived usefulness (PU) \\
2 & 3.36 & 1.155 & \\
3 & 3.40 & 1.140 \\
4 & 3.41 & 1.133 & \\
5 & 3.43 & 1.150 & \\
\hline 6 & 4.35 & .650 Organisation (ORG) \\
7 & 4.19 & .696 & \\
8 & 4.12 & .696 \\
9 & 4.08 & .753 \\
\hline 10 & 4.15 & .685 Collaboration (COL) \\
11 & 4.24 & .664 & \\
\hline 12 & 4.13 & .734 Evaluation (EVA) \\
13 & 4.08 & .741 & \\
14 & 3.65 & .945 & \\
15 & 4.27 & .677 & \\
16 & 4.00 & .806 & \\
\hline 17 & 3.92 & .874 Perceived value of learning (PVL) \\
18 & 4.00 & .770 \\
19 & 4.04 &
\end{tabular}

\section{Correlations}

As reflected in Table 3, moderate to high significant interrelations were found among: (1) PVL and the rest of the factors, and (2) between any two self-directed learning processes (Taylor, 1990). However, given the significant correlation between the PU and the processes of self-directed learning factors namely the ORG, COL, and EVA factors, the relationships were relatively weak, with the coefficient of determination $r^{2}$ ranging from .04 to .10. This suggested a low percentage of the total variation in the dependent variable was explained by the variation in the independent variable (Taylor, 1990). While these results provided preliminary insight into the relationships between the factors, the use of bivariate correlation measures did not furnish adequate information for making final conclusions to address the research questions. Multiple linear regression was considered a more comprehensive approach to examine the interconnections of the different variables and the prediction of the dependent variable from the independent ones.

Table 3

Pearson bivariate correlation coefficients

\begin{tabular}{|c|c|c|c|c|c|c|c|}
\hline Factors & Mean & $\begin{array}{l}\text { Standard } \\
\text { deviation }\end{array}$ & PVL & PU & ORG & $\mathrm{COL}$ & EVA \\
\hline PVL & 3.99 & .74 & $(.90)$ & & & & \\
\hline PU & 3.40 & 1.10 & $.39 * *$ & $(.98)$ & & & \\
\hline ORG & 4.18 & .59 & $.60 * *$ & $.23 * *$ & $(.87)$ & & \\
\hline $\mathrm{COL}$ & 4.20 & .64 & $.52 * *$ & $.21 * *$ & $.65 * *$ & $(.89)$ & \\
\hline EVA & 4.03 & .62 & $.51 * *$ & $.32 * *$ & $.65 * *$ & $.64 * *$ & $(.85)$ \\
\hline
\end{tabular}

Note. ${ }^{* *} p<.001$ (2-tailed). $N=226$. (Cronbach's alpha values are given in parentheses)

\section{Multiple linear regression}

As mentioned earlier, multiple linear regression analysis was conducted to gain insight into the prediction of learners' perceived value of learning from the other four variables. The multiple regression model significantly predicted perceived value of learning $\left(F[4,221]=45.16, p<.001\right.$, adj. $\left.R^{2}=.44\right)$. All variables, except for the EVA variable, were positive and significant predictors of perceived value of learning. The means and standard deviations of the variables can be found in Table 3 while the summary status of the regression coefficients and standard errors of the variables is shown in Table 4. 
Table 4

Regression coefficients and standard errors of variables in the scale

\begin{tabular}{|c|c|c|c|c|}
\hline \multirow[b]{2}{*}{ Independent variable } & \multicolumn{4}{|c|}{$\begin{array}{c}\text { Dependent variable }=\text { Perceived value of } \\
\text { learning }(\text { PVL })\end{array}$} \\
\hline & $B$ & $S E$ & $\beta$ & $\mathrm{t}$ \\
\hline (Constant) & .27 & .29 & & .93 \\
\hline Self-directed learning proc & & & & \\
\hline Organisation (ORG) & .49 & .09 & .39 & $5.44 * *$ \\
\hline Collaboration (COL) & .19 & .08 & .17 & $2.37 *$ \\
\hline Evaluation (EVA) & .08 & .09 & .07 & .98 \\
\hline Technological aspect: & & & & \\
\hline Perceived usefulness (PU) & .16 & .04 & .24 & $4.55 * *$ \\
\hline
\end{tabular}

Note. $B=$ unstandardised regression coefficient; $S E=$ standard error of the coefficient; $\beta=$ standardised coefficient; $* p<.05 ; * * p<.001 ; 2$-tailed, $N=226$.

\section{Discussion}

\section{What are the perceptions of the learners towards e-portfolio usage?}

From the analysis of descriptive statistics, it was evidenced that the learners generally had a good perceived process of self-directed learning as well as perceived value of learning using e-portfolios for the cluster of lessons in the module. Learners were deemed to be aware of the deadlines for completing the tasks of the lessons, and have shared their findings and views with team mates. Most importantly, team members generally helped to connect the key pieces of information collectively. However, learners generally had relatively lower endorsement for the usefulness of the e-portfolio implemented. From the learners' perspectives, it appeared that more could be done to enhance their work productivity and efficiency as well as effectiveness in learning through the use of e-portfolios. It is noteworthy that the learners' perceptions of organisation of work as well as collaboration effort between team members were high, indicating that these processes of self-directed learning were highly practiced in the use of e-portfolios. Nonetheless, the process of making written records on learning processes in the e-portfolio was not as well perceived by the learners as compared to the other items in the EVA factor. This might not be too surprising since the learners might have used other storage platforms (such as Google docs, the learning management system, or even paper notepad) to record their learning progresses. There is also a possibility that learners might not have even registered their learning on any form of written record.

\section{What is the relationship between the processes of self-directed, perceived usefulness of the e-portfolio platform and perceived value of learning?}

As substantiated by the model testing approaches based on the combination of EFA and CFA, the model for studying the perception of value of learning to facilitate self-directed learning in e-portfolios fitted the data well. Hence, the factors that emerged from this model served to be good indicators of the ability of learners to be cognisant of the self-directed learning processes in the e-portfolio platform as well as the value derived from learning in such an environment.

Based on the correlational study, there existed a significantly high positive correlation between each selfdirected learning sub-construct, namely, ORG, COL, and EVA, and overall perceived value of learning (PVL) of learners. The statistical analysis showed that the processes employed in carrying out self-directed learning have a high relationship to the value of learning perceived by learners. In addition, the processes of self-directed learning, ORG and EVA, as well as COL and EVA, were closely related to each other in the correlational analysis, in close alignment to the theory advocated in the formative evaluation model (Wolf, 1994). On the other hand, the perceived usefulness of e-portfolios seemed to have a relatively lower score in relation to the processes of self-directed learning. This suggested a need to enhance user training on using Padlet and to promote Padlet in an earlier phase of curriculum delivery so as to convince learners of the usefulness of this technological platform in supporting self-directed learning skills. In addition, early adoption of this tool would ensure learners become more adept at using it and in turn increase their platform usefulness perception. 


\section{To what extent do the processes of self-directed learning and perceived usefulness of the e-portfolio platform influence the perceived value of learning towards e-portfolio usage?}

The multiple linear regression results indicated that a significant predictive model for studying the perceived value of learning via learners' perception of processes of self-directed learning experience and usefulness of e-portfolios was established. In this study, the theoretical model was able to explain $44 \%$ of the variability in the perceived usefulness of e-portfolios and processes of self-directed learning to perceived value of learning experience. It was not surprising that the ORG variable was the most influential predictor of perceived value of learning experience as learners were observed by lecturers to make use of Padlet significantly to document their findings, results and reports. While COL emerged as a significant predictor for perceived value of learning experience, it was a relatively lower association evincing that learners might have collaborated with fellow team mates or the lecturer using other interaction and sharing modes such as verbal discussions and digital collaboration. In fact, this phenomenon was also observed in the result findings in the correlational analysis. Hence, there should be more focus on promoting sound pedagogical strategy on encouraging information sharing and collaboration between learners-vis-learners as well as scaffolding between learners-vis-lecturers through the use of e-portfolios. In addition, the processes of reflection and self-reflection allow individuals to review past performed strategies or decisions made, and in turn carry out re-evaluation if necessary. In light of this, self-directed learning is often associated with reflection. In fact, critical reflection is a prerequisite for self-directed learning to take place (Gencel \& Saracaloglu, 2018). However, the EVA variable was an insignificant contributor of learners' perception towards the value of learning. From hindsight, a plausible explanation for this observation could be that learners carried out reflection in their reflection journal hosted on the institution's learning management system. As such, the usage of the e-portfolio as a reflection tool was kept to a minimum. In addition, learners could also have done their analysis and evaluation of the problem statement in the lesson via other means rather than on the e-portfolio. As a result, it was deemed necessary to strengthen the aspects of reflection and connection using e-portfolios to help learners optimally achieve the desired effect derived from self-directed learning. To improve in this aspect, learners should be encouraged to conduct their planning, organising, selecting, reflecting, sharing, and connecting of information primarily on the Padlet tool. Furthermore, it appeared that the PU variable was a moderate significant predictor of perceived value of learning experience of learners involved in solving this larger problem package. This was encouraging to the curriculum designer and team as PU is an important indicator of students' acceptance of the use of Padlet as an e-portfolio (Davis, 1989).

\section{Implications for practice}

The results of this study have practical implications for the curriculum team of the described module, because it increases understanding of how e-portfolios could be introduced in the module as an effective eportfolio tool to promote students' self-directed learning. It is especially important for the investigated institution which has adopted problem based learning as its predominant instructional strategy in the classrooms. This study has demonstrated that Padlet is a promising tool to be used in scaffolding students to practice self-directed learning. On a positive note, it has also been verified that students found the eportfolio to be useful in their learning. For learning areas that are related to team selection of key information in the larger problem and subsequently the reflection performed on feedback given by various stakeholders, it must be explicitly communicated to the students to perform these tasks using the e-portfolio medium. In a similar manner, if more focus could be given using the e-portfolio as the primary communication medium to share findings and views between learners, teams, and lecturer, then learners would be more inclined to attribute the EVA aspect of learning to their perceived value of learning.

Last but not least, this study shows that the perceived value of learning derived from using e-portfolios as a tool to scaffold self-directed learning processes is not just dependent on examining the learners' perception of their learning processes. It also requires the careful orchestration of different domains such as the technological aspect (PU of the platform), learning process aspect (ORG, COL, and EVA) as well as the affective aspect (PVL), in order to comprehensively assess the e-portfolio usage in promoting selfdirected learning. 


\section{Limitations and future research}

Firstly, a limitation to the research study was the exploration and confirmation of a new model after gaining insights from Wolf's (1994) formative evaluation model about the facilitation of self-directed learning through the use of e-portfolios. While this study attempted to confirm the proposed model satisfactorily, the question remains whether this study really measured well-formed propositions towards the new teaching tool, Padlet, which could change over time. Due to the cross-sectional nature of the present study, further direction could be skewed towards adopting a longitudinal approach or mixed methods research on the learners' perception of learning and learning processes in the use of an e-portfolio to support learning. This is pertinent in making more robust conclusions about the stability of the researched model under study.

Secondly, the user acceptance of the technological aspect of the newly introduced Padlet tool could be fully investigated as this study focussed only on the perceived usefulness of the technology used. In this aspect, the full or extended technology acceptance model (TAM) could be utilised in future research to examine users' belief variables (perceived ease of use and usefulness), affective variable (attitude to use), and behavioural variable (intention to use) as well as other relevant antecedent variables (Davis, 1985). While this study provided the perception of learners towards Padlet as an effective pedagogical tool in promoting self-directed learning, it is also critical to focus on the position of teachers towards the use of the e-portfolios in facilitating learning and potentially examines the different ways in which it could help in the area of formative or even summative assessment in terms of continuous assessment grading.

Thirdly, this study is primarily a quantitative research study. Qualitative research, using focus group discussion approach could provide more insights into the specific ways learners use e-portfolios in their learning. as well as the challenges faced in adopting this tool. Interviews with the lecturers could also help to understand the constraints faced in facilitating teams' discussion, sharing, and presentation via eportfolios. Indeed, the benefits of learning derived from the use of e-portfolios are more important than mere fashionable implementation of the technological tool.

In sum, this study contributes to the literature on the learners' perception of the value of learning derived from an e-portfolio tool to engage in self-directed learning processes. It furthers the discussion on subsequent use of e-portfolios in other lessons as a mean of formative evaluation of learners' learning. Most pertinently, it allows the team responsible for the described module to consider the future curriculum, pedagogical, delivery, and assessment direction of the module and any change, if necessary, that needs to be effected.

\section{References}

Abdullah, F., Ward, R., \& Ahmed, E. (2016). Investigating the influence of the most commonly used external variables of TAM on students' perceived ease of use (PEOU) and perceived usefulness (PU) of e-portfolios. Computers in Human Behavior, 63(1), 75-90.

https://doi.org/10.1016/j.chb.2016.05.014

Abu Awwad, F. M. (2013). The impact of electronic portfolio on developing reflective thinking and selfdirected learning readiness. Cypriot Journal of Educational Sciences, 8(1), 78. http://www.cjes.eu/

Barret, B. (2010). E-Portfolio programs as strategic tools for implementation and evaluation. Review of Business Research, 10(2), 56-62. https://rbr-journal.org/RBR-JOURNAL/Default.aspx

Beckers, J. (2019). Walking the tightrope with an e-portfolio: Imbalance between support and autonomy hampers self-directed learning. Journal of Vocational Education \& Training, 71(2), 260-288. https://doi.org/10.1080/13636820.2018.1481448

Bhatiasevi, V. (2011). Acceptance of e-learning for users in higher education: An extension of the technology acceptance model. The Social Sciences, 6(6), 513-520.

Biggs, J. (2001). The revised two-factor study process questionnaire: R-SPQ-2F. British Journal of Educational Psychology, 71(1), 133-149. https://doi.org/10.1348/000709901158433

Britland, J. (2019). Developing self-directed learners through an eportfolio peer consultant program. International Journal of ePortfolio, 9(1), 45. https://eric.ed.gov/?id=EJ1214593

Butler Lamar, S. C., Samms-Brown, C., \& Brown Iii, U. J. (2016). Technology acceptance in a sample of college students. International Journal of Education Research, 11(1), 15-26.

Byrne, B. M. (2010). Structural equation modeling with AMOS: Basic concepts, applications, and programming (2nd ed.). Routledge. 
Chen, M. -Y., Chang, M. -T., Chen, C. -C., Huang, M. -J., \& Chen, J. -W. (2012). Why do individuals use e-portfolios? Journal of Educational Technology \& Society, 15(4), 114-125. https://www.jstor.org/stable/pdf/jeductechsoci.15.4.114.pdf

Ciesielkiewicz, M. (2019). The use of e-portfolios in higher education: From the students' perspective. Issues in Educational Research, 29(3), 649-667. http://www.iier.org.au/iier29/ciesielkiewicz-abs.html

Cristobal, E., Flavián, C., \& Guinalíu, M. (2007). Perceived e-service quality (PeSQ): Measurement validation and effects on consumer satisfaction and web site loyalty. Managing Service Quality: An International Journal, 17(3), 317-340. https://doi.org/10.1108/09604520710744326

Davis, F. D. (1985). A technology acceptance model for empirically testing new end-user information systems: Theory and results. (Doctoral dissertation). Massachusetts Institute of Technology, Massachusetts. http://hdl.handle.net/1721.1/15192

Davis, F. D. (1989). Perceived usefulness, perceived ease of use, and user acceptance of information technology. MIS Quarterly, 13(3), 319-340. https://doi.org/10.2307/249008

Deci, E. L. (1991). Motivation and education: The self-determination perspective. Educational Psychologist, 26(3-4), 325-346. https://doi.org/10.1080/00461520.1991.9653137

Deci, E. L. (1994). Facilitating internalization: The self-determination theory perspective. Journal of Personality, 62(1), 119-142. https://doi.org/10.1111/j.1467-6494.1994.tb00797.x

De La Fuente, J., Cardelle-Elawar, M., Peralta, F., Sanchez, M., Martinez, J., \& Zapata, L. (2011). Students' factors affecting undergraduates' perceptions of their teaching and learning process within ECTS experience. Frontiers in Psychology, 2:28. https://doi.org/10.3389/fpsyg.2011.00028

Garthwait, A., \& Verrill, J. (2003). E-portfolios: Documenting student progress. Science and Children, $40(8), 22$. https://search.proquest.com/openview/afb004e7af47b72f2bb698eecdeda821/1?cbl=41736\&pqorigsite $=$ gscholar

Gencel, I. E., \& Saracaloglu, A. S. (2018). The effect of layered curriculum on reflective thinking and on self-directed learning readiness of prospective teachers. International Journal of Progressive Education, 14(1), 8-20. https://doi.org/10.29329/ijpe.2018.129.2

Goliath, C. L. (2009). Diffusion of an e-Portfolio to assist in the self-directed learning of physicians: An exploratory study. (Doctoral dissertation). University of Akron, Ohio.

Hair, J. F., Black, W. C., Babin, B. J., Anderson, R. E., \& Tatham, R. L. (1998). Multivariate data analysis (Vol. 5). Prentice Hall.

Huang, Y. C. (2006). E-portfolios: Their impact on self-directed learning and computer technology skills on preservice teachers. (Doctoral dissertation). University of Missouri-Saint Louis, Missouri.

Jaryani, F., Zandi, B., Sahibudin, S., Salehy, S., Masrom, M., \& Zamani, M. (2010, May 7-10). Framework of a reflective e-portfolio supported by outcome based education and problem based learning. Paper presented at the Second International Conference on Computer Research and Development, Egypt. https://ieexplore.ieee.org/abstract/document/5489537

Kline, R. B. (2015). Principles and practice of structural equation modeling. Guilford Publications.

Knowles, M. S. (1975). Self-directed learning: A guide for learners and teachers (Vol. 2). Association Press.

Kwok, L. (2011). College students' participation in e-portfolio learning in relation to academic ability and motivation. Electronic Journal of Foreign Language Teaching, 8(2), 246-267. http://e-flt.nus.edu.sg/

McNeill, M., \& Cram, A. (2011, December 4-7). Evaluating e-portfolios for university learning: Challenges and opportunities. Paper presented at the ASCILITE - Australian Society for Computers in Learning in Tertiary Education Annual Conference 2011, Tasmania.

Rahmi, B., Burak, B., \& Adnan, A. (2018). A meta analysis of factors affecting perceived usefulness and perceived ease of use in the adoption of e-learning systems. Turkish Online Journal of Distance Education, 19(4), 4-42. https://doi.org/10.17718/tojde.471649

Rosseel, Y. (2011). Lavaan: Latent variable analysis. R package version 0.3-3.

Spector, P. E. (1992). Summated rating scale construction: An introduction. Sage.

Strampel, K., \& Oliver, R. (2007, December 2-5). Using technology to foster reflection in higher education. Paper presented at the ICT: Providing Choices for Learners and Learning. Proceedings Ascilite 2007, Singapore. http://www.ascilite.org.au/conferences/singapore07/procs/strampel.pdf

Taylor, R. (1990). Interpretation of the correlation coefficient: A basic review. Journal of Diagnostic Medical Sonography, 6(1), 35-39. https://doi.org/10.1177/875647939000600106

Teo, T. (2009). Is there an attitude problem? Reconsidering the role of attitude in the TAM. British Journal of Educational Technology, 40(6), 1139-1141. https://doi.org/10.1111/j.14678535.2008.00913.x 
Tuksinvarajarn, A. (2009). The E-Pet: Enhancing motivation in e-portfolios. English Teaching Forum, 47(1), 22-31. https://eric.ed.gov/?id=EJ923726

Ursavaş, Ö. F. (2013). Reconsidering the role of attitude in the TAM: An answer to Teo (2009) and Nistor and Heymann (2010), and Lopez-Bonilla and Lopez-Bonilla (2011) Colloquium. British Journal of Educational Technology, 44(1), E22-E25. https://doi.org/10.1111/j.14678535.2012.01327.x

Vaisman, J. C. (2012). Development of a measure of the perceived learning process in graduate student internship. (Doctoral dissertation). New York University, New York.

West, S. G., Finch, J. F., \& Curran, P. J. (1995). Structural equation models with nonnormal variables: Problems and remedies. In R. Hoyle (Ed.), Structural equation modeling: Concepts, issues and applications (pp. 56-75). Sage.

Wolf, K. (1994). Teaching portfolios: Capturing the complexity of teaching. In L. Ingvarson, \& R. Chadbourne (Eds.), Valuing teachers' work: New directions in teacher appraisal (pp. 112-136). Australian Council for Education Research.

Corresponding author: Boon Khing Song, song_boon_khing@rp.edu.sg

Copyright: Articles published in the Australasian Journal of Educational Technology (AJET) are available under Creative Commons Attribution Non-Commercial No Derivatives Licence (CC BY-NCND 4.0). Authors retain copyright in their work and grant AJET right of first publication under CC BYNC-ND 4.0.

Please cite as: Song, B. K. (2021). E-portfolio implementation: Examining learners' perception of usefulness, self-directed learning process and value of learning. Australasian Journal of Educational Technology, 37(1), 68-81. https://doi.org/10.14742/ajet.6126 